\title{
Peranan Orang Tua Terhadap Tingkat Penggunaan Media Online Remaja di Jakarta
}

\author{
Johanes Witoro ${ }^{\text {a }}$ 1* $^{*}$ \\ ${ }^{\text {a }}$ STT Biblika Jakarta \\ 1Johaneswitoro@gmail.com * \\ *korespondensi penulis
}

\section{Informasi artikel}

Received :

July 02, 2019.

Revised :

July 31, 2019.

Publish :

August 31, 2019.

Kata kunci:

AnakRemaja

Pengaruh Media

Online

Peran Orang Tua

\section{Keywords:}

Teenagers

Influence of Online

Media

The role of parents

\begin{abstract}
ABSTRAK
Tidak bisa dipungkiri, pengaruh positif dan juga negatif dari media online bisa mempengaruhi emosi, intelektual, dan psikologi anak-anak remaja masa kini. Disinilah dibutuhkan peranan orang tua, terutama dalam membentengi dan mengatasi pengaruh-pengaruh negatif dari media online yang ada saat ini. Penelitian ini dimaksudkan untuk mencari hubungan antara peran orang tua terhadap anak remaja mereka yang menggunakan media online dalam kehidupan sehari-hari mereka. Peran orang tua yang siginifikan diharapkan mampu mengtasi pengaruh negatif anak-anak remaja saat ini.Penelitian ini menggunakan metode kuantitatif, yang melibatkan siswa-siswi di sekolah menengah atas sebagai responden utama. Pengambilan data melaui kuisoner yang diberikan kepada siswa-siswi di sekolah menengah atas.Dapat disimpulkan bahwa peranan orang tua memiliki pengaruh yang signifikan dalam penggunaan media online oleh siswa-siswi di sekolah menengah atas. Maka dari itu, diperlukan kerjasama dari orang tua di rumah dan guru di sekolah, dan juga pelibatan anak remaja dalam menghadapi pengaruh negatif media online saat ini.
\end{abstract}

\begin{abstract}
The role of parents towards teenagers in facing the influence of online media.It is undeniable that the positive and negative influences of online media can affect the emotional, intellectual and psychological aspects of today's teenagers. This is where the role of parents is needed, especially in fortifying and overcoming the negative influences of the online media that exist today. This research is intended to find a relationship between the role of parents and their teenagers using online media in their daily lives. The significant role of parents is expected to be able to investigate the negative influence of teenagers today. This study uses a quantitative method, which involves students from senior high school as the main respondents. Retrieval of data through a questionnaire given to students of senior high school. It can be concluded that the role of parents has a significant influence in the use of online media by students of senior high school. Therefore, collaboration between parents at home and teachers at school is needed, and also the involvement of adolescents in dealing with the negative effects of online media today.
\end{abstract}

Copyright $\odot 2019$ (Johanes Witoro). All Right Reserved

How to Cite: Witoro, Johanes. (2019). Peranan Orang Tua Terhadap Tingkat Penggunaan Media Online Remaja di,Jakarta. Jurnal Inspirasi Pendidikan, 9(2), 139-146.

This work is licensed under a Creative Commons Attribution-ShareAlike 4.0 International License. Allows readers to read, download, copy, distribute, print, search, or link to the full texts of its articles and allow readers to use them for any other lawful purpose. The journal holds the copyright. 


\section{Pendahuluan}

Perkembangan media online telah merubah cara interaksi satu individu dengan individu yang lain. Tidak dapat dihindari bahwa keberadaan media online memberikan banyak kemudahan kepada penggunanya. Beragam akses terhadap informasi, hiburan, peljaran, bahkan pertemanan dari berbagai penjuru dunia dapat diakses dengan mudah melalui media online. Dapat dikatakan, media online saat ini menembus batas dimensi kehidupan pengguna, waktu, dan ruang, yang dapat diakses oleh siapapun, kapanpun, dan dimanapun (Ayun, 2015; Niemer, 2012). Penggunaan media online dikalangan remaja memberikan pengaruh langsung, baik positif maupun negatif. Remaja yang sering menggunakan media online bisa mengganggu proses belajar mereka (Pratiwi, 2017). Secara prilaku anak remaja cenderung mengikuti apa saja yang dilihat dan diakses secara online. Inilah sebabnya anak remaja cenderung mempraktekkan apa yang telah di lihatnya secara online. Seperti halnya, melakukan kekerasan, pelecehan seksual, prilaku-prilaku yang menyimpang lainnya. Menurut data yang di dapat melalui survei yang dilakukan Kompas (2014) diketahui bahwa pengguna internet di Indonesia yang berasal dari kalangan anak-anak dan remaja diprediksi mencapai 30 juta. Penelitian ini juga mencatat ada kesenjangan digital yang kuat antara anak dan remaja yang tinggal di perkotaan dengan yang tinggal di pedesaan (Kompas, 2014). Dari data tersebut, sekitar 80 persen, remaja aktif dalam media online.

Kata media berasal dari bahasa Latin, yang merupakan betuk jamak dari kata medium, yang berarti sesuatu yang terletak di tengah (antara dua pihak atau kutub) atau suatu alat. Dalam Webster (1983:110), media atau medium adalah segala sesuatuyang terletak di tengah dalam bentuk jenjang, atau alat apa saja yang digunakan seebagai perantara atau penghubung dua pihak atau dua hal. Oleh karena itu, media pembelajaran dapat diartikan sebagai sesuatu yang mengantarkan pesan pembelajaran antara pemberi pesan kepada penerima pesan.

Menurut Crish Garret, media online adalah alat, jasa, dan komunikasi yang memfasilitasi hubungan antara orang dengan satu sama lain dan memiliki peminat yang banyak tidak terkecuali para remaja, bahkan usia dibawah umur sudah memiliki akun media online sendiri. Munculnya berbagai macam media online memberikan pengaruh langsung baik positif maupun negatif.Dunia remaja terkhusus disini anak-anak SMA, diyakini merupakan pengguna internet terbesar di Indonesia, terutama media online. Hampir semua anak SMA yang memiliki gawai (handphone, tablet, dan laptop), pasti memiliki akun media online (Pratiwi, 2017).

Berbagai penelitian penggunaan Internetdi kalangan remaja di atas menunjukkan bahwaInternet telah menjadi bagian yang tidak dapatdipisahkan dari kehidupan sehari-hari anakanak dan remaja di Indonesia. SehinggaKemenkominfo memandang perlu ada berbagaiupaya untuk meningkatkan kesadaran,pengetahuan dan keterampilan mereka dalamkaitannya dengan keamanan ber-internet. Hal inidapat dicapai melalui sosialisasi, pendidikanliterasi maupun pelatihan (Halim, 2015).

Saat ini, banyak orangtua mungkin ketinggalan dari anak-anak mereka dalam hal menguasai dan menggunakan media online, sedikit dari orangtua yang mengawasi anak-anak mereka ketika mengakses internet, dan sedikit yang menjadi 'teman' anaknya dalam media online (Kominfo, 2014; Varghese\& Nivedhitha, 2012). Oleh karena itu, orang tua sebagai orang terdekat dari anak-anak remaja (siswa SMA), memiliki peran sentral dalam membentengi dan meminimalisir pengaruh negatif dari media online saat ini. Banyak orang tua yang belum sadar, bahwa gawai yang mereka berikan kepada anak mereka memiliki dampak dan pengaruh negatif bagi kehidupan anak-anak mereka. Orang tua harus faham, bahwa orang tua dan dunia internet saat ini tidak bisa tidak, harus berperan dalam kehidupan anaknya sehari-hari (Chassiakos, $d k k$. 2016). Dari sinilah kami merasa bahwa perlu adanya penelitian tentang pengaruh media online ini dan peranan orang tua dalam menghadapi pengaruh media online ini.

\section{Metode Penelitian}

Metode penelitian yang digunakan dalam penelitian ini adalah penelitian kuantitatif deskriptif. Penelitian ini dilakukan di SMA yang berada di Jakarta Utara. SMA ini dipilih karena kami anggap mewakili dua variabel yang kami teliti yaitu: (1) Peranan orang tua dan (2) Pengaruh media online. Untuk pengambilan data, peneliti menggunakan 2 jenis kuisoner untuk 2 variabel yang diteliti. Setiap kuisoner terdapat 20 item pertanyaan, dengan 4 skala linkert; Sangat Setuju (SS), Setuju (S), Tidak 
Setuju (TS), dan Sangat Tidak Setuju (STS). Penelitian ini dilakukan pada tanggal 5 - 6 September 2019 di SMA yang berlokasi di Jakarta Utara. Penelitian ini mengambil sampel berjumlah 30 siswasiswi dari kelas 10 sampai kelas 12 . Usia para responden antara $15-18$ tahun, dengan asal daerah yang berbeda-beda.

\section{Hasil dan Pembahasan}

Setelah melakukan pengambilan data di SMA yang berlokasi di Jakarta Utara pada tanggal 5-6 September 2019, peneliti mendapat hasil dari kuisoner ditunjukkan oleh Gambar 1.

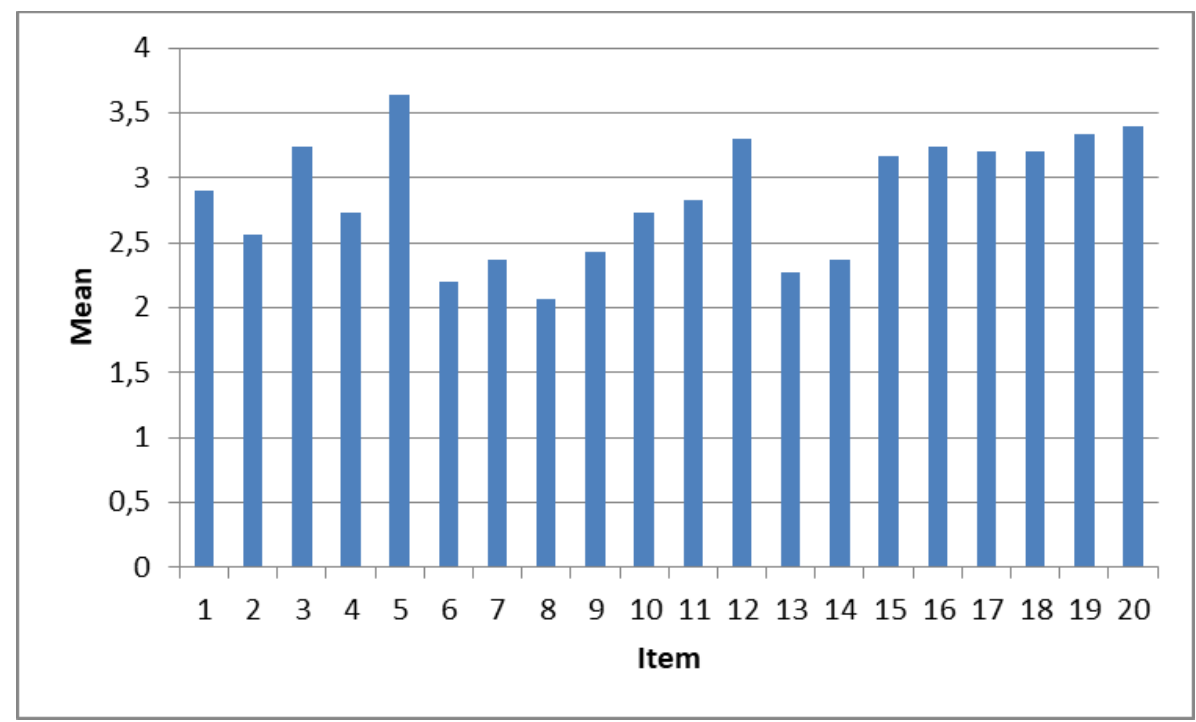

Gambar 1. Hasil dari Kuisoner Variabel Peranan Orang Tua

Gambar 1 menunjukkan nilai rerata untuk masing-masing indikator item kuesioner variabel peranan orang tua. Hasil menunjukkan bahwa semua item memiliki nilai rerata di atas 2, sehingga didapatkan deskipsi bahwa orang tua memiliki peranan penting pada penggunaan media online. Dari data pada Gambar 1, didapatkan gambaran bahwa orang tua setuju untuk menyediakan saranaprasarana untuk mengakses informasi secara online, mengatur penggunaan media online, dan memberikan dukungan untuk belajar memakai media online. Orang tua tidak setuju untuk memberikan kebebasan penuh pada anak untuk menggunakan gawai dan memakai media online.

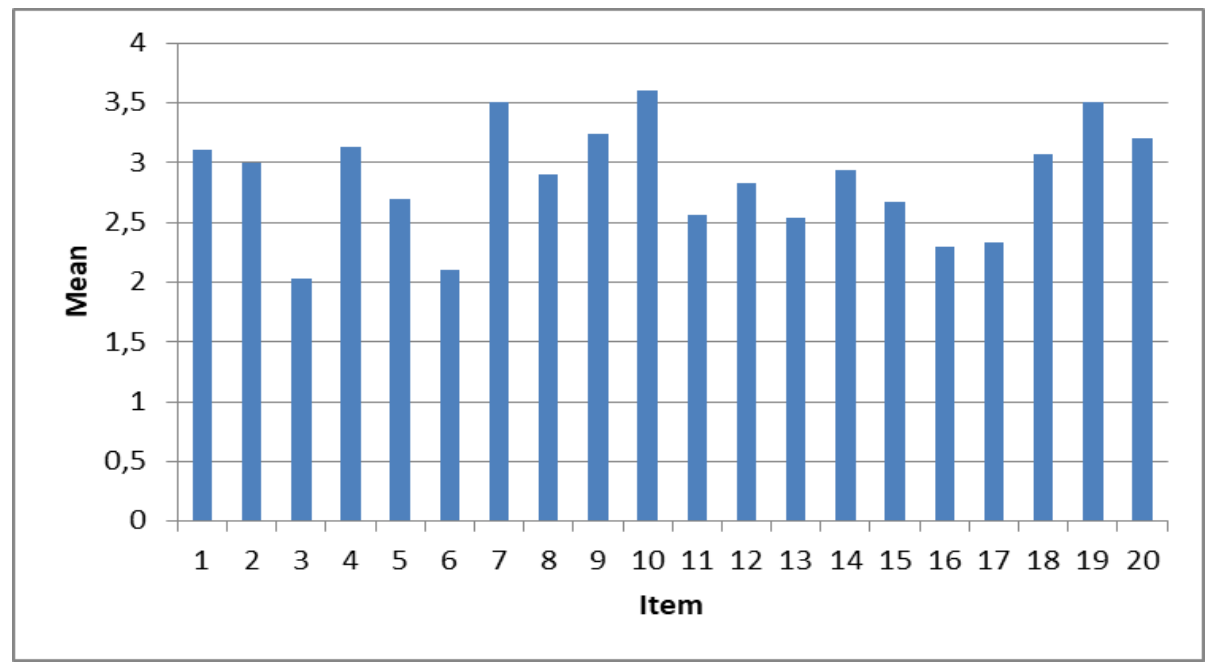

Gambar2. Hasil dari Kuisoner Variabel Pengaruh Media Online 
Gambar 2 menunjukkan nilai rerata untuk masing-masing indikator item kuesioner variabel pengaruh media online. Hasil menunjukkan bahwa semua item memiliki nilai rerata di atas 2, sehingga didapatkan deskipsi bahwa pengaruh media online cukup signifikan terjadi pada keseharian siswa-siswi di SMA. Dari Gambar 2, didapatkan gambaran bahwa pengaruh terbesar media online adalah sebagai alat komunikasi dalam kehidupan remaja, media online digunakan dengan intensitas yang sangat tinggi/penggunakan media online secara berlebihan oleh anak-anak remaja, adanya penggunaan media online sebagai sarana belajar, adanya anggapan bahwa pengguna media online adalah semua kalangan, tidak hanya anak-anak remaja, dan banyak yang tidak setuju ketika media online digunakan sebagai sarana bermain game dan belanja secara online.

Selanjutnya nilai rerata dan simpangan dihitung menggunakan metode statistika untuk mengetahui ukuran pemusatan dan penyebaran data. Hasil perhitungan ukuran pemusatan dan penyebaran data ditunjukkan oleh Tabel 1.

Tabel 1. Peranan Orang Tua terhadap Anaknya di SMA

\begin{tabular}{rlccc}
\hline No & \multicolumn{1}{c}{ Variabel } & Rata-Rata & Standar Deviasi & Variansi \\
\hline 1 & Peran Orang Tua (X) & 72.42 & 10.70 & 114.58 \\
2 & Penggunaan Media Sosial (Y) & 74.85 & 10.06 & 101.11 \\
\hline
\end{tabular}

Dari data pada Tabel 1, didapatkan gambaran bahwa orang tua setuju untuk menyediakan saranaprasarana untuk mengakses informasi secara online, mengatur penggunaan media online, dan memberikan dukungan untuk belajar memakai media online. Orang tua tidak setuju untuk memberikan kebebasan penuh pada anak untuk menggunakan gawai dan memakai media online.

Penentuan pengaruh antara variabel independen (bebas) terhadap variabel dependen (terikat) dan seberapa besar pengaruhnya akan dilakukan pada kasus ini, sehingga kita akan menggunakan statistik uji berupa regresi linear. Aplikasi statistik uji yang dilakukan dalam analisis kasus ini adalah SPSS. Lalu, uji prasyarat analisis statistik regresi (linearitas dan independensi) harus dipenuhi dan dihitung terlebih dahulu untuk menentukan variabel bebas mana sajakah yang memiliki pengaruh terhadap variabel terikat. Tabel 2 menunjukkan hasil uji prasyarat analisis untuk regresi linear.

Tabel 2. Tabel Uji Prasyarat Regresi

\begin{tabular}{llccccc}
\hline & & Sum of Squares & $\mathrm{df}$ & $\begin{array}{c}\text { Mean } \\
\text { Square }\end{array}$ & $\mathrm{F}$ & Sig \\
\hline $\begin{array}{l}\text { Rerata_peran } \\
\text { orang }\end{array}$ & Between Groups & 6408.305 & 30 & 246.476 & 34.715 & .000 \\
tua_penggunaan & (Combined) & & & & & \\
media sosial & Linearity & 6074.203 & 1 & 6072.602 & 855.214 & .000 \\
& $\begin{array}{l}\text { Deviation from } \\
\text { Linearity }\end{array}$ & 333.871 & 29 & 13.356 & 1.882 & .201 \\
& Within Groups & 34.500 & 5 & 7.102 & & \\
\cline { 2 - 7 } & Total & 6443.872 & 35 & & & \\
\hline
\end{tabular}

Pada table 2 linearity tersebut dapat dilihat bahwa nilai signifikansi $(0.000)<$ signifikansi $(0.05)$, maka dapat disimpulkan bahwa variabel peran orang tua bersifat independen (variabel peran orang tua tidak dipengaruhi oleh variabel lain). Pada kolom deviation from linearity dapat dilihat bahwa nilai signifikansi $(0.250) \geq$ signifikansi (0.05), sehingga dapat disimpulkan bahwa variabel peran orang tua (X) memiliki hubungan yang linear dengan variabel penggunaan media sosial (Y). Variabel X bersifat independen dan linear. Hal ini menunjukkan bahwa variabel $\mathrm{X}$ memenuhi prasyarat analisis untuk uji statistik regresi linear, sehingga variabel $\mathrm{X}$ dapat dianalisis dengan uji statistik regresi linear. Variabel bebas dalam kasus ini adalah variabel peran orang tua. Dan variabel terikat dalam kasus ini adalah variabel penggunaan media sosial. Hipotesis nol $\left(\mathrm{H}_{0}\right)$ pada penelitian ini adalah tidak ada pengaruh peran orang tua terhadap penggunaan media sosial. Hipotesis alternatif $\left(\mathrm{H}_{\mathrm{a}}\right)$ pada penelitian ini adalah ada pengaruh peran orang tua terhadap penggunaan media sosial. Tabel 3 dan 4 menunjukkan hasil uji regresi linear antara variabel bebas $(\mathrm{X})$ dan variabel terikat $(\mathrm{Y})$. 


\begin{tabular}{lcccc}
\multicolumn{5}{c}{ Tabel 3. Hasil Uji Regresi Linear } \\
\hline \multirow{4}{*}{ Model } & $\mathrm{R}$ & R Square & Adjusted R & Std. Error of the \\
& & & Square & Estimate \\
1 & .971 & .943 & .941 & 3.509 \\
\hline \multicolumn{2}{c}{ a. Predictors: (Constant), Peran_Orang_Tua } \\
\hline
\end{tabular}

Berdasarkan tabel 3 dapat diketahui koefisien korelasi antara peran orang tua dengan penggunaan media online adalah 0.971 . Hal ini menunjukan bahwa kekuatan hubungan pada kategori sangat tinggi. Kolom $\mathrm{R}$ square ini menunjukkan nilai determinasi. Nilai determinasi berada pada rentang $50 \%-100 \%$ yakni $94.3 \%$ (0.943) yang menunjukkan bahwa $94.3 \%$ variasi penggunaan media online remaja dapat dijelaskan oleh variasi peran orang tua. Berdasarkan tabel 3 dapat diketahui juga bahwa standard error adalah 3,509, hasil ini menunjukkan bahwa semakin kecil standard error semakin tepat dalam memprediksi penggunaan media online.

Tabel 4. Hasil Uji Regresi Linear

\begin{tabular}{|c|c|c|c|c|c|}
\hline \multirow{2}{*}{ Model } & \multicolumn{2}{|c|}{ Unstandardized Coefficient } & $\begin{array}{c}\text { Standardized } \\
\text { Coefficient }\end{array}$ & \multirow[t]{2}{*}{$\mathrm{t}$} & \multirow[t]{2}{*}{ Sig } \\
\hline & B & Std. Error & $\mathrm{B}$ & & \\
\hline 1 (Constant) & 5.623 & 2.501 & & 2.248 & 0.032 \\
\hline Peran Orang Tua & .943 & .042 & .971 & 22.212 & 0.000 \\
\hline
\end{tabular}

Tabel 4 ini menunjukkan nilai regresi dari antara peran orang tua dengan penggunaan media online. Berdasarkan pengujian hipotesis dengan uji t. Berdasarkan kolom t dan Sig dapat dilihat bahwa t hitung (22.212) $\geq \mathrm{t}$ kritis $(2.042)$ dan $P$ value $(0.00)<$ signifikansi $(0.05)$ dengan $\beta=0,971$, sehingga H0 ditolak (Ha Diterima) sehingga dapat disimpulkan bahwa ada pengaruh peran orang tua terhadap penggunaan gawai dan media sosial pada anak.

\section{Pembahasan}

Peranan orang tua dalam mengawasi dan mengkontrol penggunaan media online remaja di SMA memiliki pengaruh positif terhadap keseharian anak-anak di sekolah. Hal ini penting karena, penggunaan internet dan media sosial yang tidak ada kontrol atau pengawasan dari orang tua merupakan salah satu sebab mengapa remaja saat ini menjadi kecanduan dan terkena dampak negatif dari penggunaan media sosial yang berlebihan (Putri $d k k$., 2016; Endah $d k k$., 2017; Sobring, 2014).

Hasil penelitian ini menunjukkan bahwa anak-anak SMA menggunakan gawai mereka untuk berbagai macam hal, terkhusus penggunaan untuk media online/media sosial. Dari media online, beberapa belajar materi pelajaran, ada yang bermain game, ada berbelanja online, dan kebanyakan menggunakannya sebagai saran komunikasi dengan teman-temannya, baik teman dunia nyata maupun teman dunia maya. hal ini masih wajar selama tidak berlebihan, karena penggunaan media sosial yang berlebihan akan menjadikan si anak remaja kecanduan media social dan mengabaikan sekelilingnya (Young, 2009).

Media sosial seperti halnya internet, memiliki dampak positif dan negatif (O'Keeffe\& ClarkePearson, 2011; Tartari, 2015). Dampak negatif media sosial sangat banyak macamnya, dari cyber bullying, pornografi, komunikasi yang buruk,ujaran kebencian, bahkan gangguan kesehatan dikarenakan penggunaan yang berlebihan (Fitri, 2017; Sengupta\& Chaudhuri, 2011; Strasburger $d k k$, 2012). Cyberbullying sendiri jika tidak ditangani secara serius melalui pengawasan orang tua sebagai pemberi sarana anak berselancar di dunia maya, maka akan mengakibatkan si anak akan membawa cyberbullying ini ke dunia nyata dan mencari sasaran teman yang dapat di-bully. Dia akan juga membully teman-temannya, atau kalau ia korban, makai akan depresi dan stres, sehingga mengganggu kehidupan sehari-harinya (Alim, 2016; Fisher, 2013). 
Anak-anak siswa-siswi SMA di Jakarta Utara yang menjadi sampel dalam penelitian ini menunjukkan ketergantungan mereka pada internet. Sebagian besar dari mereka memiliki akun media social dan aktif dalam menggunakannya. Seharusnya anak remaja harus bisa memposisikan media online/media sosial sebagai partnernya dalam belajar, dan orang tua harus bisa memposiskan dirinya sebagai pembimbing bagaimana seharusnya penggunaan media online/media sosial yang benar dan tepat (Belch $d k k$., 2005; Sorbring\& Lundin, 2012).

Orang tua berperan penting dalam penggunaan gawai dan media sosial anak karena orang tua meegang kendali dalam keluarga sebagai fasilitator penyedia kontrol. Sesuai dengan hasil penelitian yang didapatkan, peran orang tua berpengaruh pada penggunaan gawai dan media sosial anak. Orang tuaPenelitian yang dilakukan oleh Permano (2013), menunjukan ada hubungan peran orang tua dalam mangoptimalisasi tumbuh kembang anak untuk membangun karakter anak, dan peran stimulasi orang tua sangat berarti bagi perkembangan anak, dengan demikian peran orang tua memiliki pengaruh terhadap perkembangan anak

Orangtua saat ini diasosiasikan sebagai digital immigrant atau penduduk pendatang yang masih berusaha beradaptasi di dunia digital sebagai salah satu hasil dari perkembangan teknologi yang baru, orangtua sebagai digital immigrant dituntut untuk melakukan adaptasi secara instan terhadap teknologi yang marak digunakan oleh anak remajanya. Kurangnya pengetahuan orangtua terhadap situs jejaring sosial karena perbedaan persepsi yang ada diantara orangtua dan remaja.

Persepsi merupakan pengalaman tentang objek, peristiwa, atau hubungan-hubungan yang diperoleh dengan menyimpulkan informasi dan menafsirkan pesan. Persepsi ialah memberikan makna pada stimulus indrawi (Endah $d k k$., 2017). Maka dari itu sebaiknya orang tua juga harus mengerti dahulu mengenai dunia sosial media agar bisa memilah mana yang baik dan buruk dan tidak berdampak buruk seperti anak menjadi malas belajar berkomunikasi di dunia nyata, mereka menjadi tidak sadar lingkungan karena terlalu banyak menghabiskan waktu untuk bermain media sosial. Jika media online terebut digunakan sebagai media pembelajaran, maka bisa jadi pengaruh yang baik terhadap anak akan menjadi pengaruh yang baik pula.

Media online sudah sering digunakan sebagai media pembelajaran. Di posisi itulah peran orang tua menjadi penting dalam penggunaan media online. Orang tua bisa memposisikan media online sebagai saran belajar yang multirepresentatif. Salah satu fungsi utama media pembelajaran aadalah sebagai alat bantu dalam proses pembelajaran yang turut mempengaruhi iklim, kondisi dan lingkungan belajar yang ditata dan diciptakan oleh guru (Arsyad, 2013: 19). Media pembelajaran, menurut Kemp dan Dauton (1985: 28), dapat memenuhi tiga fungsi utama apabila media itu digunakan untuk perorangan atau individu, kelompok, atau kelompok pendengar yang besar jumlahnya, yaitu: Memotivasi minat atau tindakan, menyajikan informasi, dan memberi instruksi.

Menurut Arsyad (2011: 26-27) beberapa manfaat media pembelajaran adalah media pembelajaran dapat memperjelas penyajian pesan dan informasi sehingga dapat memperlancar dan meningkatkan proses hasil belajar, media pembelajaran dapat meningkatkan dan mengarahkan perhatian anak sehingga dapat menimbulkan motivasi belajar, interaksi yang lebih langsung antara siswa dan lingkungannya dan memungkinkan siswa untuk belajar sendiri-sendiri sesuai dengan kemampuan dan minatnya, dan media pembelajaran dapat mengatasi keterbatasan indera, ruang, fasilitas, dan waktu pada anak dan sekolah.

Berbagi informasi dan gambar melalui media sosial adalah bagian dari kehidupan sehari-hari bagi banyak anak dan remaja. Media sosial memungkinkan anak-anak untuk berkomunikasi satu sama lain, dan untuk mendokumentasikan dan berbagi apa yang mereka lakukan secara real time. Kekuatan jejaring media sosial berarti bahwa tidak jarang bagi anak-anak untuk terhubung dengan orang-orang yang belum pernah mereka temui secara langsung.

Baik itu melalui pesan teks atau aplikasi smartphone seperti Instagram atau Snapchat, anak-anak dan remaja saat ini dapat berbagi informasi pribadi jauh melebihi apa yang bisa dilakukan orang tua mereka ketika mereka masih muda. Penting bagi orang tua untuk mempelajari tentang berbagai teknologi yang digunakan anak-anak untuk membantu menjaga mereka tetap aman saat online. Media sosial selalu berubah, dengan aplikasi baru yang muncul setiap saat. Karena dokumen ini hanya pengantar, kami telah menyertakan tautan ke situs web lain yang mungkin Anda temukan bermanfaat. 
Media sosial secara luas dipandang sebagai sumber informasi yang berguna dan sebagai salah satu alat pengasuhan anak di antara sekumpulan pilihan. Ibu menggunakannya sebagai sumber daya pengasuhan sedikit lebih sering daripada ayah.

Sementara sebagian besar orang tua menemukan nilai di media sosial sebagai sumber informasi umum, lebih sedikit yang mengatakan mereka menemukan informasi pengasuhan yang bermanfaat saat menggunakan media sosial. Pada saat yang sama, satu dari empat mengatakan mereka mendapat dukungan dari jaringan mereka untuk masalah pengasuhan, dan ibu yang menggunakan media sosial lebih dari tiga kali lebih mungkin dibandingkan ayah yang mengatakan mereka mendapat dukungan.

Beberapa orang tua mengatakan mereka merasa tidak nyaman ketika informasi tentang anakanak mereka dibagikan oleh anggota keluarga lain atau pengasuh di media sosial. Sebagian besar orang tua tidak merasa gelisah tentang konten yang diposting tentang anak-anak mereka oleh anggota keluarga lain atau pengasuh di media sosial.

\section{Simpulan}

Dapat disimpulkan bahwa siswa-siswi SMA merupakan anak-anak remaja yang kehidupan sehari-harinya terpengaruh oleh media online saat ini. Hasil penelitian ini menunjukkan bahwa peranan orang tua memiliki pengaruh yang signifikan dalam penggunaan media online oleh siswasiswi SMA yang berada di Jakarta utara pada khususnya dan di indonesia pada umumnya. Maka dari itu, diperlukan kerjasama dari orang tua dan guru, dan juga pelibatan anak remaja dalam menghadapi pengaruh negatif media online saat ini.

\section{Referensi}

Alim, S. (2016). Cyberbullying in the world of teenagers and social media: A literature review. International Journal of Cyber Behavior, Psychology and Learning (IJCBPL), 6(2), 68-95.

Arsyad, Azhar. 2013. Media Pembelajaran. Jakarta: RajawaliPers.

Ayun, P. Q. (2015). Fenomena remaja menggunakan media sosial dalam membentuk identitas. Jurnal Channel, 3(2), 1-16.

Belch, M. A., Krentler, K. A., \& Willis-Flurry, L. A. (2005). Teen internet mavens: influence in family decision making. Journal of Business Research, 58(5), 569-575.

Chassiakos, Y. L. R., Radesky, J., Christakis, D., Moreno, M. A., \& Cross, C. (2016). Children and adolescents and digital media. Pediatrics, 138(5), e20162593.

Endah, T., Dimas, A., Akmal, N., \& Indonesia, F. U. (2017). Kajian Dampak Penggunaan Media Sosial Bagi Anak dan Remaja.

Fisher, E. (2013). From Cyber Bullying to Cyber Coping: The Misuse of Mobile Technology and Social Media and Their Effects on People's Lives. Business and Economic Research, 3(2), 127-145.

Fitri, S. (2017). Dampak positif dan negatif sosial media terhadap perubahan sosial anak. Naturalistic: Jurnal Kajian Penelitian Pendidikan dan Pembelajaran, 1(2), 118-123.

Halim, N. A. (2015). Penggunaan Media Internet di Kalangan Remaja Untuk Mengembangkan Pemahaman Keislaman. Jurnal Dakwah Risalah, 26(3), 132-150.

Kemp, J.E. danDauton, D.K. 1985.Planing and Producing Instructional Media (Fifth Adition).New York: Herper\& Row Publishers.

Kominfo, P. (n.d.). Siaran Pers No. 17/PIH/KOMINFO/2/2014 tentang Riset Kominfo dan UNICEF Mengenai Perilaku Anak dan Remaja Dalam Menggunakan Internet. Retrieved from https://kominfo.go.id/index.php/content/detail/3834/siaran pers no. 17pikominfo22014 tentang riset kominfo dan unicef mengenai perilaku anak dan remaja dalam menggunakan internet /0/siaran_pers

Niemer, E. (2012). Teenagers and social media. Alive: Canada's Natural Health \& Wellness Magazine, 20-29. 
O'Keeffe, G. S., \& Clarke-Pearson, K. (2011). The impact of social media on children, adolescents, and families. Pediatrics, 127(4), 800-804.

Pratiwi, A. (2017, April 28). Pengaruh Media Sosial Bagi Remaja. Retrieved from https://www.kompasiana.com/amipratiwi18/5902e5578c7e61e71b2c3016/pengaruh-mediasosial-bagi-remaja

Putri, W. S. R., Nurwati, N., \& Budiarti, M. (2016). Pengaruh media sosial terhadap perilaku remaja. Prosiding Penelitian dan Pengabdian kepada Masyarakat, 3(1).

Sengupta, A., \& Chaudhuri, A. (2011). Are social networking sites a source of online harassment for teens? Evidence from survey data. Children and Youth Services Review, 33(2), 284-290.

Sorbring, E. (2014). Parents' concerns about their teenage children's Internet use. Journal of Family Issues, 35(1), 75-96.

Sorbring, E., \& Lundin, L. (2012). Mothers' and fathers' insights into teenagers' use of the internet. New Media \& Society, 14(7), 1181-1197.

Strasburger, V. C., Jordan, A. B., \& Donnerstein, E. (2012). Children, Adolescents, and the Media: Health Effects. Pediatric Clinics, 59(3), 533-587.

Tartari, E. (2015). Benefits and risks of children and adolescents using social media. European Scientific Journal, 11(13).

Varghese, T., \& Nivedhitha, D. (2012). Social Media in Family Communication of Teenagers-A Focus Group Discussion. Media Watch, 3(2), 3-10.

Wahyudi, R. (2014). Hasil Survei Pemakaian Internet Remaja Indonesia. Retrieved from https://tekno.kompas.com/read/2014/02/19/1623250/Hasil.Survei.Pemakaian.Internet.Remaja. Indonesia?page=all, diakses 12 September 2019.

Young, K. (2009). Internet addiction: diagnosis and treatment considerations. Journal of Contemporary Psychotherapy, 39(4), 241-246. 